\title{
Optimum energy consumption by using kinetic shading system for residential buildings in hot arid areas
}

\author{
Mostafa M. S. Ahmed ${ }^{\mathrm{a} *}$, Ali K. Abdel-Rahman ${ }^{\mathrm{b}}$, Mahmoud Bady ${ }^{\mathrm{c}}$, Essam K. \\ Mahrous $^{\mathrm{d}}$, M. Suzuki ${ }^{\mathrm{e}}$ \\ ${ }^{a}$ PhD student at Energy Resources Engineering, Egypt-Japan University of Science and Technology, Alexandria, Egypt. \\ ${ }^{b}$ Chairperson of Department of Energy Recourses Engineering at Egypt-Japan University of Science and Technology \\ ${ }^{c}$ Assistant Professor at Energy Resources Engineering, Egypt-Japan University of Science and Technology, Alexandria, Egypt. \\ ${ }^{d}$ Head of the Department of Architectural Engineering, Faculty of Engineering, Assiut University, Alexandria, Egypt. \\ ${ }^{e}$ Vice president of Egypt-Japan University of Science and Technology, Alexandria, Egypt.
}

\begin{abstract}
In the last decades, development of innovative solutions is considered as a prominent issue for achieving sustainability within the built environment. Facades are crucial to energy consumption and comfort within buildings. Incorporating intelligence in their design is an effective way to minimize energy consumption buildings. The ability of specific facade systems to work reliably and effectively is one of the challenges toward sustainable buildings environment. One of the most important methods of saving energy in a building is by carefully designing its facade. A 'kinetic facade' can be considered as an optimally one of the best options in managing the interaction between the outdoors and the internal spaces. It also provides some architectural flexibility to the design. Kinetic Façade building is one of the available energy conservation opportunities through recent intelligent buildings. This paper reports the results of using a new intelligent kinetic shading system to investigate how it can improve the internal conditions and decrease the energy consumption within residential building in hot arid areas. Finally, the results of the case study show that monthly adaptation of kinetic shading facade system can lead to improved and decreased the internal temperature of the building about 4-5 degree Celsius and 18-20\% energy savings compared to the normal building without shading system.
\end{abstract}

Keywords: Kinetic facade, energy saving, automated control, residential building.

\section{Introduction}

Climate considerations are essential dimensions in the assessment of thermal comfort and indoor environments inside Egyptian housing. Energy conservation in buildings is taking central attention in Egypt on the public, designers and decision makers' levels triggered by the fear electricity supply shortage in 2012 and 2013. In buildings sector which consumes about 42\% of energy in Egypt.

Over the past few decades, kinetic facades have emerged as alternative building envelopes, designed to meet the increasing of varying and complex demands related to user comfort, energy consumption and cost efficiency. This concept has been described in a number of ways, ranging from the usage of innovative components to highly complex designs and advance technological application [1].

Nowadays many architectures designers of dynamic building skins that reconfigure themselves in changing conditions have utilized mechanical systems. On the other hand, when designing for dynamic responsiveness, these systems often involve intricate and high-tech mechanistic joints, actuators and control [2]. Facades are crucial to energy consumption and comfort within buildings. Incorporating intelligence in their design is an effective way to achieve low energy consumption buildings [3]. some

*Manuscript received November 30, 2015; revised April 3, 2016.

Corresponding author. E-mail address: mostafa.ahmed@ejust.edu.eg.

doi: $10.12720 /$ sgce.5.2.121-128 
promising and innovative building envelopes tend to be more adaptive and interactive with the climate, space functions, indoor environments, occupants and visitors [4] and thus building façades are increasingly developed as complex systems of material assemblies attuned to climate and energy optimization [5].

The main purpose of this study to introduce a method for quantifying the impact of dynamic facade adaptation on residential building performance and to improve the indoor environment within these building because many of houses in Egypt are often designed without taking the climate into account sufficiently. Consequently, new houses often have a poor indoor climate, which affects comfort, health and building efficiency. In hot and arid climates, passive cooling system employs non-mechanical procedures to maintain suitable indoor temperature [6]. Thus, we measure the influence of the new kinetic shading system in energy saving.

\subsection{The develop interest of the kinetic façade.}

The explosion of technology enabled kinetic architecture to make a spectacular comeback and attack traditional architecture, due to the powerful combination of manufacturing and use of technologies, sustained by kinetic architecture [7] therefore, technological advancements and innovations for designing dynamic architectural skin present new opportunities for designers and architects [8]. and thus building façades are increasingly developed as complex systems of material assemblies attuned to climate and energy optimization [5].

The use of kinetic facades has been adopted since the 1960s. being the one of the first examples responsive building skin of the Los Angeles County Hall of Records, designed by Richared Neutra in 1962 [9]. Another early example of automated climate-adaptive envelopes was Buckminster Fuller's façade for the United States pavilion built for the 1967 Montreal Expo. The skin of this geodesic dome was made of a transparent cladding of acrylic panels, as shown in Fig. 1, with interior canvas sunshades controlled by a computer program that would adjust their position relative to the movement of the sun [5].

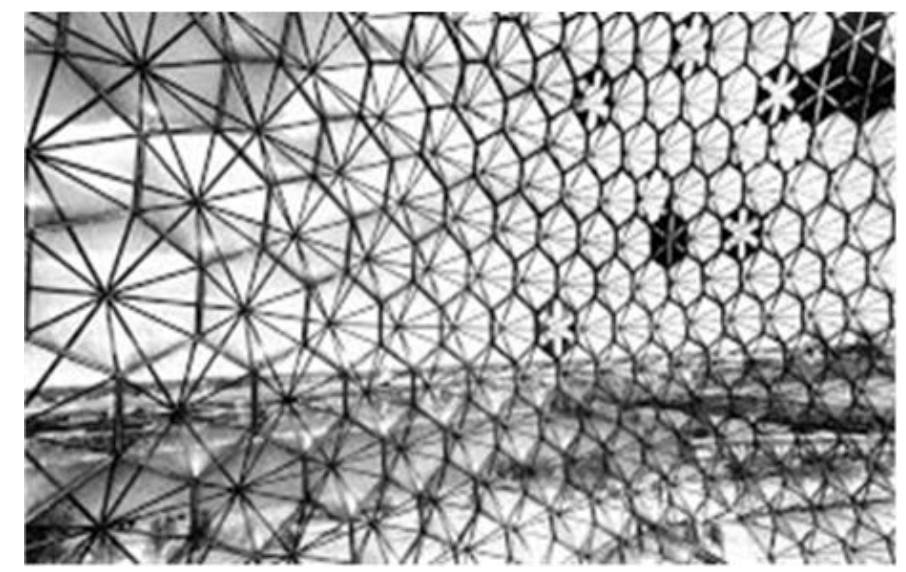

Fig. 1. The canvas sunshades in Montreal Expo Dome by Buckminster Fuller's 1967 [10].

In addition, this kinetic response is designed and demonstrated by the famous Jean Nouvel kinetic facades, Monde de Arabe (1980) [8] which hundreds of sliding planes (25,000 photoelectric cells similar to a camera lens) were motorized and placed within the façade. Various sensors measure daylight and open or close the irises as necessary to control lighting levels. the system using complex motorizations and an enormous amount of motorization [11].

Furthermore, engineering firm Buro Happold, in collaboration with deployable structures innovator Chuck Hoberman, have established an intelligent surfaces unit called The Adaptive Buildings Initiative (ABI). This design unit Has developed a number of kinetic shading and cladding systems, including the Strata ${ }^{\mathrm{TM}}$ System, which consists of automated modular kinetic units that can retract into a slender profile 
(Fig. 2). The Strata ${ }^{\mathrm{TM}}$ system was the basis for the Helio Trace Façade, developed in collaboration with SOM and Permasteelisa Group, that improves envelope performance relative to daylight and glare while reducing solar heat gain by approximately $81 \%$ [12]. The aluminum perforated shading surfaces work in two separate layers in response to daily sun path. Each square shaped opening/window is fully covered with 4 vertical triangular folding shading surfaces. The shading surfaces that fold out horizontally are located at edges of each window [13].

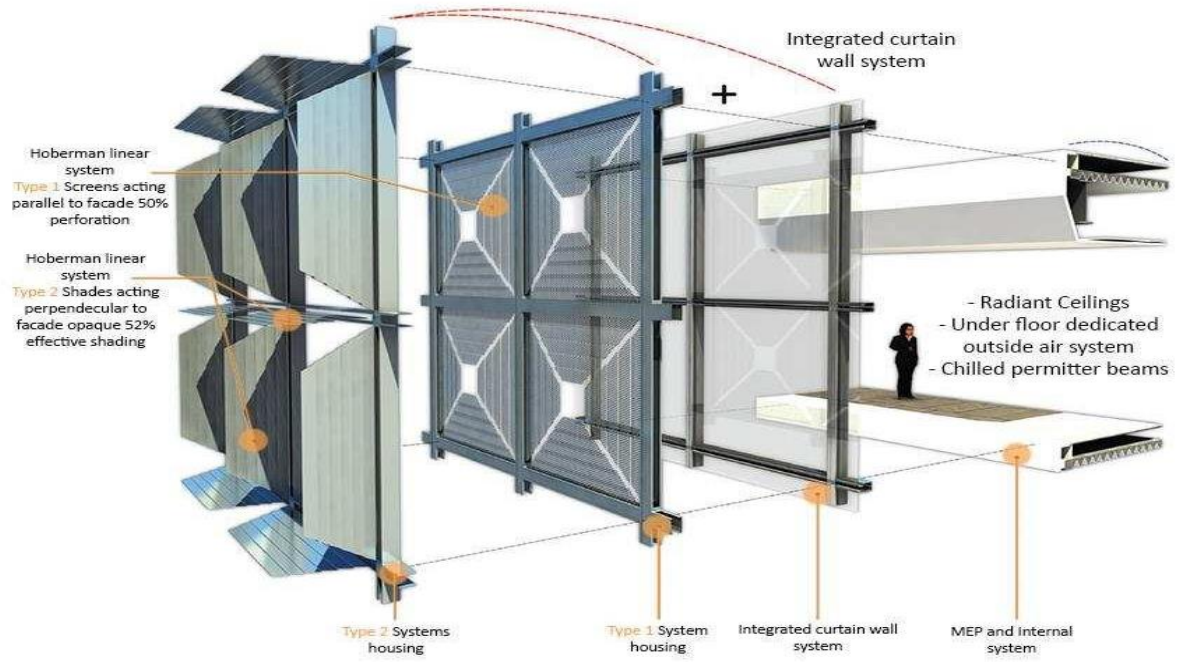

Fig. 2. The 3D section for Helio Trace Centre window unit by SOM/ABI/Permasteelisa, 2010 [14].

Nowadays, the application of responsive elements in a building, for instance kinetic facade plays an essential part in a building's operation. On the other hand, the architectural design principles and construction methods of kinetic facades have been under explored.

Among strategies and solutions used in discussing problem of a buildings' energy consumption, the buildings' façade should function as a mediator between the external and internal environments. Facades can be entrusted with multiple vital functions that dictate the building's energy consumption and which determine indoor environmental quality [15] and thus we measure the influence of the new adaptive kinetic shading system in energy consumption within residential building during the summer period in this experimental
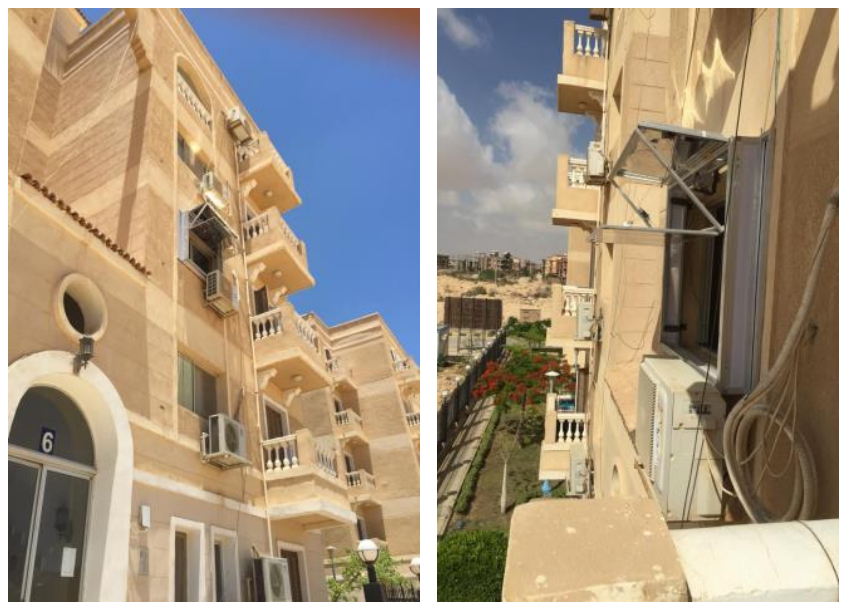

Fig. 3. Exterior view of residential building from the southeast direction of kinetic shading system 


\section{Experimental Set-up}

Experimental work conducted during the period from 20 of July to 20 August 2015. It fixed at the outer surface of the south oriented window of flat no. 9, building no. 6, at the campus of Egypt-Japan University of Science and Technology (E-JUST) as shown in Fig. 3, it located in New Borg El-Arab city Alexandria $\left(30.9^{\circ} \mathrm{N}, 29.6^{\circ} \mathrm{E}\right)$. Fig. 4 indicates schematic diagram of experimental set-up consist of Aluminum frame window of dimensions $130 * 150 \mathrm{~cm}$. In addition, it consists of two sections which can be moved vertically and rotationally respectively. The main section moved vertically up and down motion by means of DC actuator and connected wire. The minor sections can be moved by means of two servo motor with angle from 0 to $180^{\circ}$. These actuators controlled by Arduino Board which had outdoor temperature sensor as shown in Fig. 5 the stages of the operation of the kinetic system. However, setting point of control signal is $28^{\circ} \mathrm{c}$. Finally, Arduino board connected to laptop with controlling programmer software (Rhino and Grasshopper) Fig. 6 indicates the connection between Arduino board and laptop with controlling programmer software and the way of the digital servo and DC motor respond to the computer.

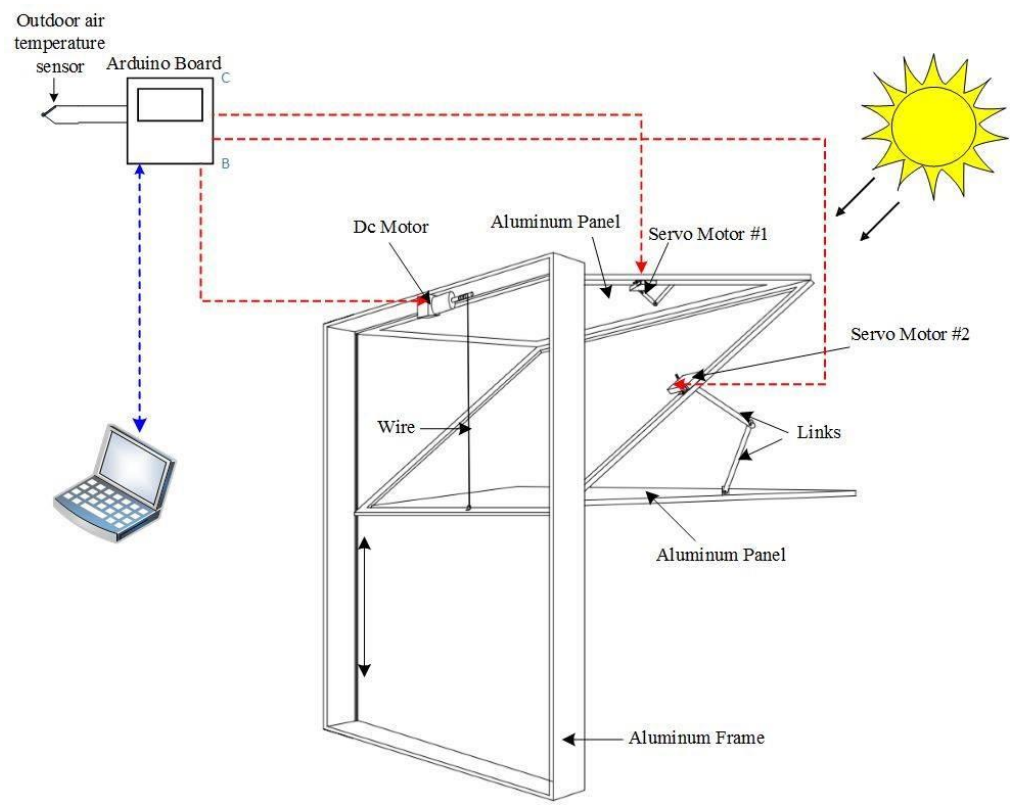

Fig. 4. The schematic diagram of the experimental set-up.

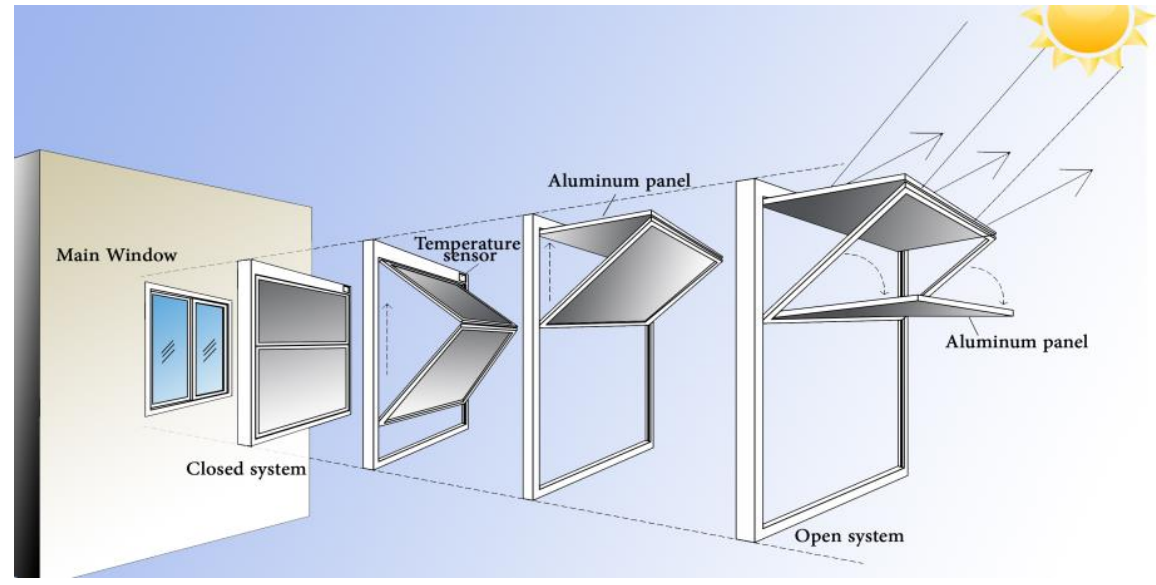

Fig. 5. Stages of the operation of the kinetic system. 

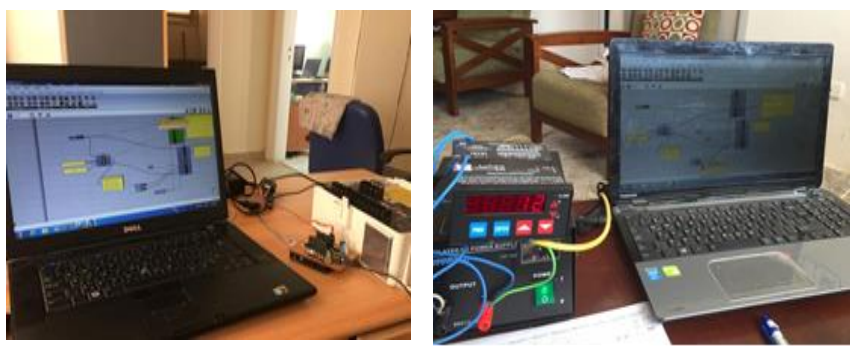

Fig. 6. The connection between Arduino board and laptop with controlling programmer software (Rhino and Grasshopper).

The experiment used to control and improve indoor thermal comfort of living room with dimensions as indicated in Fig. 7. Where indoor air velocity, indoor air temperature and indoor relative humidity measured by air velocity meter (Hot wire anemometer model number 9545/9545-A). These variables recorded simultaneously with outdoor variables every hour starting from 6:00 am to 6:00 pm, and Fig. 8 indicates the transfer of data in the adaptive kinetic shading system.

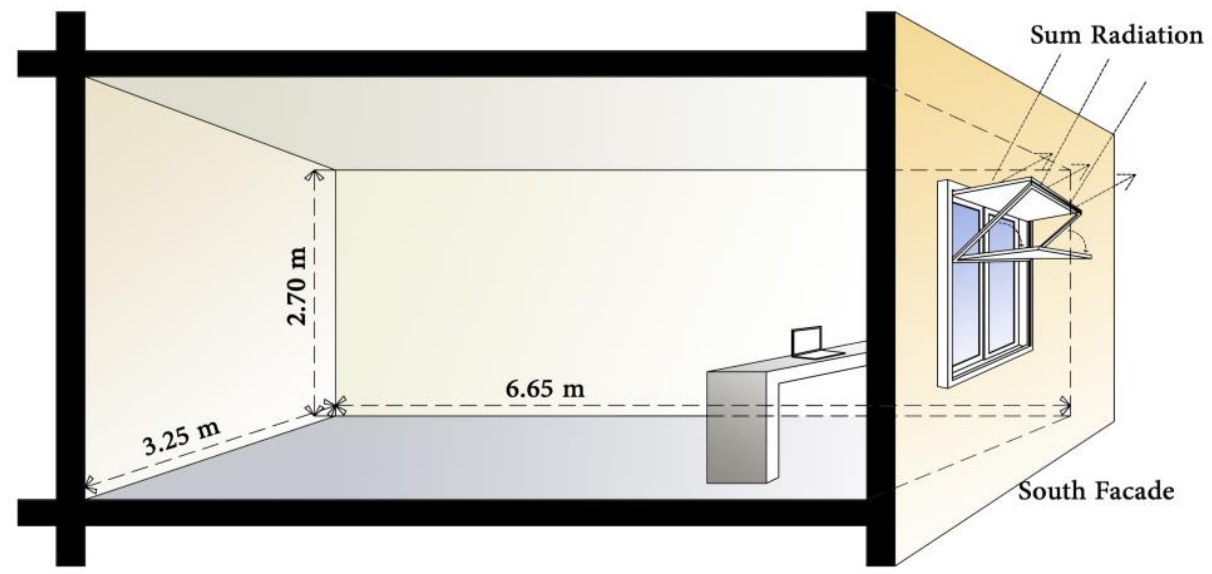

Fig. 7. 3D drawing of living room coupled with automatic shading system.

This study presents a comparison between two identical spaces, one with system and the other without system is conducted to identify the advantage of the kinetic system and its influence in energy consumption within residential building.

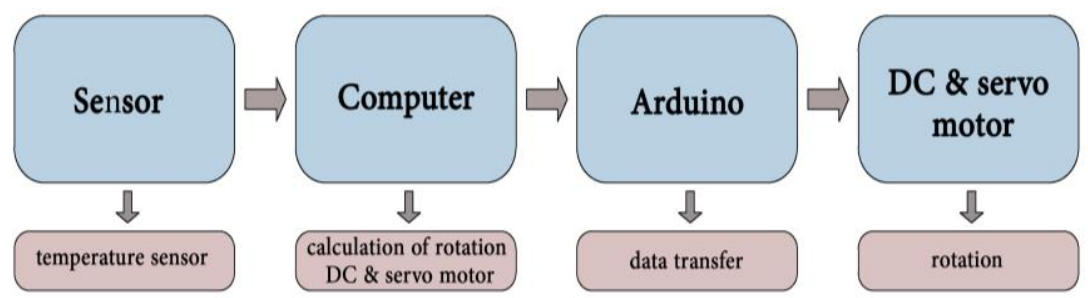

Fig. 8. The schematic diagram of the data transfer at the Kinetic shading system.

\section{Results}

\subsection{Environmental conditions}

Fig. 9 shows yearly average outdoor temperature values in Alexandria city in which the study was carried out using Consultant 5.3 software. From the figures, clearly it can be seen that August has 
maximum average temperature during the year. The maximum outdoor temperature recorded is about 32 ${ }^{\circ} \mathrm{C}$ during the daytime (6 AM - $\left.6 \mathrm{PM}\right)$.
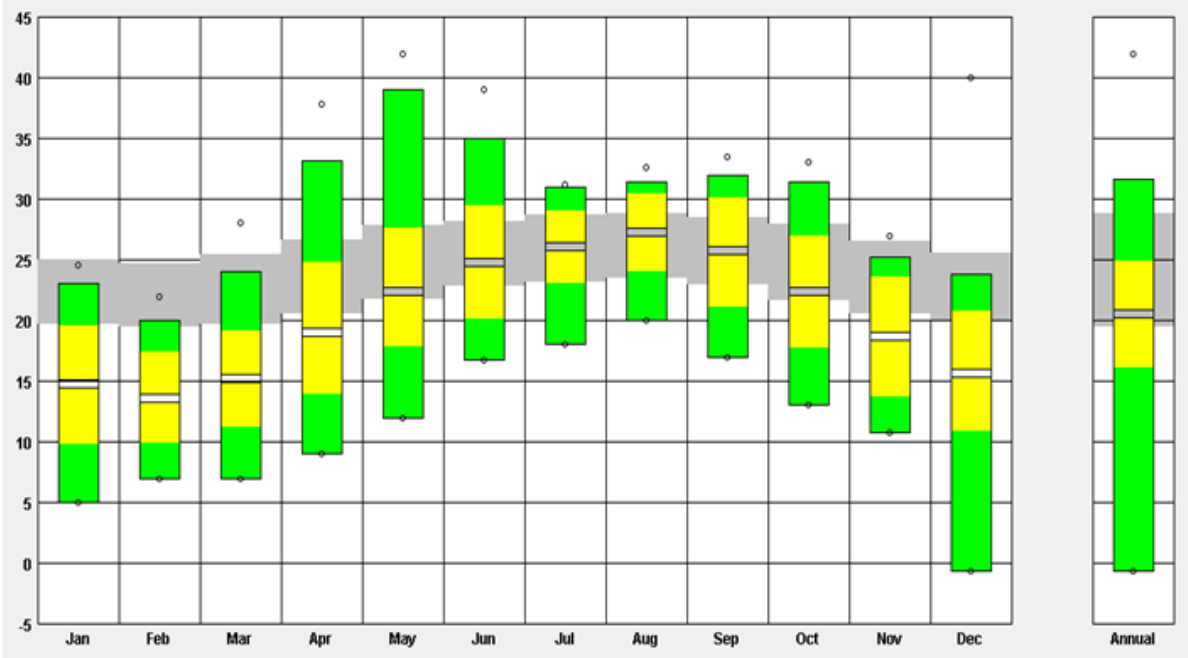

Fig. 9. Climateconsultant 5.3 temperature data of Alexandria.

In terms of the indoor thermal comfort evaluation in the presented study was determined by using the Adaptive Comfort Standard (ACS) for naturally ventilated buildings which were employed by ASHRAE standard 55 [16].

For the ACS, $80 \%$ and $90 \%$ acceptability limits of indoor operative temperature are proposed as a function of mean monthly outdoor air temperature by the following formula [17]:

$$
T_{\text {com }}=0.31\left(T_{\text {out }}\right)+17.8
$$

where $\mathrm{T}_{\text {com }}$ is the optimum comfort indoor temperature in ${ }^{\circ} \mathrm{C}$ and Tout is the mean monthly outdoor air temperature in ${ }^{\circ} \mathrm{C}$. While, the $90 \%$ acceptability limits of indoor operative temperature were calculated as follows [18]:

$90 \%$ acceptability ranges $=T_{\text {com }} \pm 2.5^{\circ} \mathrm{C}$

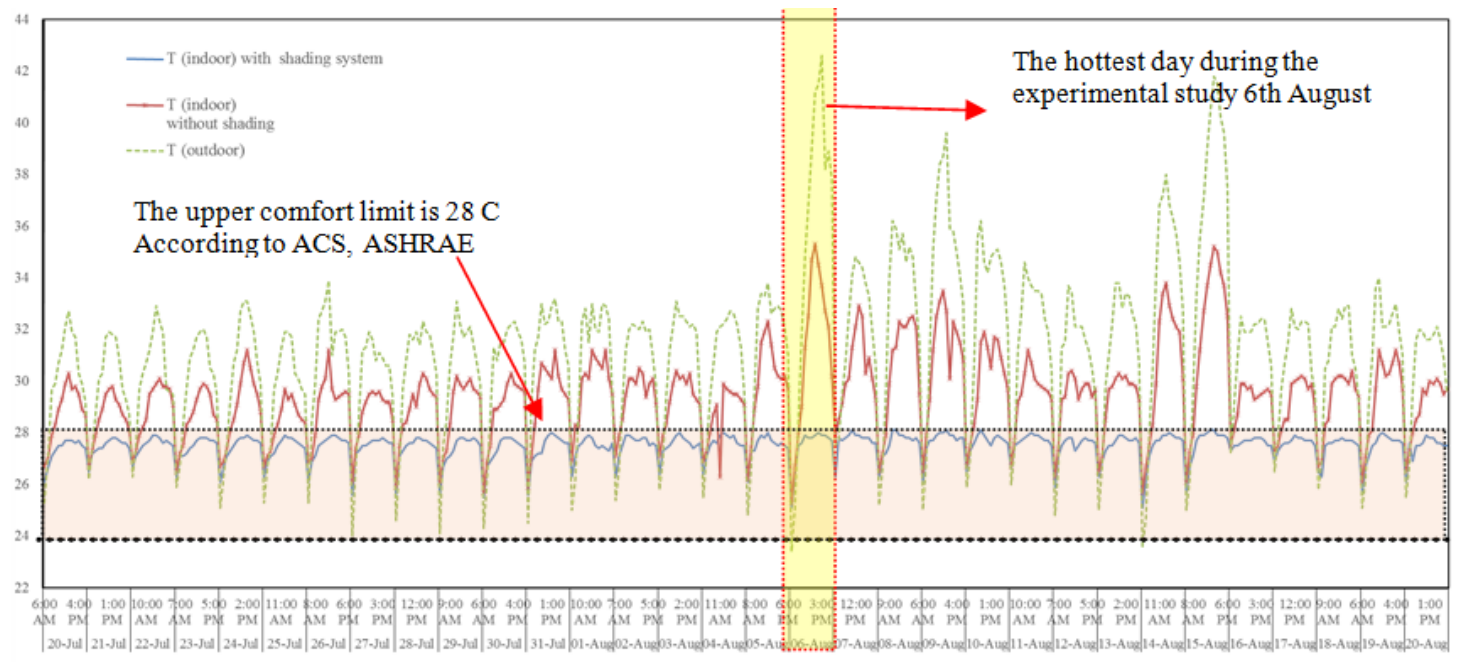

Fig. 10. Hourly indoor and outdoor air temperature. 
The measured data clearly in Fig. 10 show that there has been an increase of outdoor temperature in the measurement within the ranged from $25.5^{\circ} \mathrm{C}$ to $42.6^{\circ} \mathrm{C}$ during the day time corresponding to a rise in indoor temperature ranged from $25.5^{\circ} \mathrm{C}$ to $35^{\circ} \mathrm{C}$. As depicted from Fig. 10, the indoor temperature ranged from $25.5^{\circ} \mathrm{C}$ to $28.2^{\circ} \mathrm{C}$ while installing the proposed system on the south opening of the building.

It is clear that the kinetic shading system improve the indoor temperature and almost temperature after using system between comfort range and thus will decrease the energy consumption of the air condition and cause improve of comfort within this residential space.

\subsection{Energy savings}

Each zone of the building was physically investigated with the assistance of the building's operation in order to obtain information and data on the building lighting, equipment and occupancy. Moreover, electricity utility bills for the whole year 2015 has been collected. For the financial analysis, the cost of the energy consumption was calculated in Egyptian pound (EGP), which is referred to as operation cost. Next, the energy use within the building was measured using digital power meter for a studied period.

According to the collected results the monthly electricity consumption for the building was $450 \mathrm{~kW}$ per month (130 EGP per month). This means that the building is consuming $5 \mathrm{kWh} / \mathrm{m} 2 / \mathrm{month}$ of electrical energy. Fig. 11 shows that the electricity consumption in summer months during installing the proposed system is lower than the consumption under actual operation conditions. These savings were due to decreasing the indoor temperature of the space. As a result of decreasing the operation time of aircondition during the daytime.

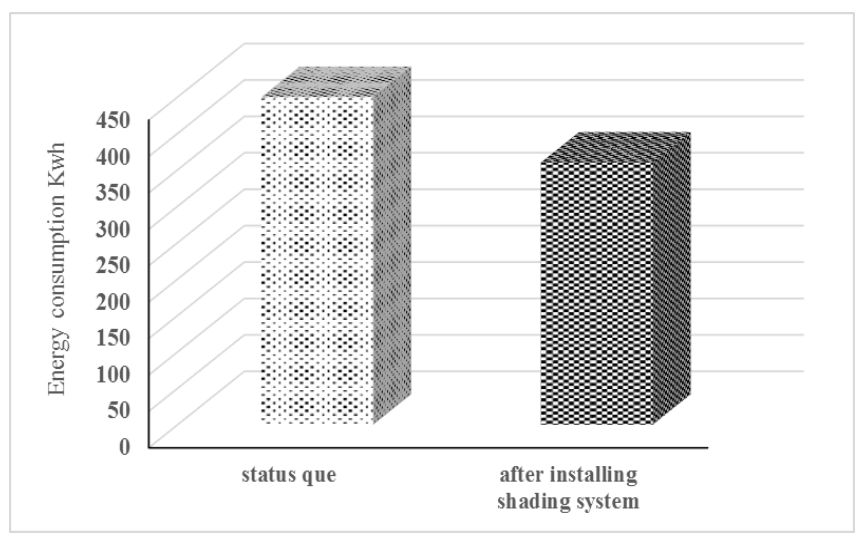

Fig. 11. Electricity consumption with and without system.

\section{Conclusion}

The application of Kinetic shading system in building can reduce the heat transmission as well as the electricity consumption of the air conditioning system, especially for the buildings located in hot aired area.

The goal of this paper was to introduce a method for quantifying the impact of dynamic facade adaptation on residential building performance and to improve the indoor environment within these building. In the present case study, the concept of adaptability of building facades adaptive with surrounding condition indicates potential advantages as it compromise energy savings while upgrading the indoor environment.

Starting from previous studies about the effect of adaptive facade for reducing building energy consumption in summer, this study aimed at experimentally assessing the intelligent kinetic façade system vs. traditional conditions without any system.

Thus, the researchers of this study propose future works and more studies to be done on kinetic facades designs, on the problems in kinetic facades designs and its impact on the environment, building 
ergonomics and human psychology, and comfort. Innovations in kinetic architecture should be further pursued and kinetic design applications in buildings should seriously be considered as an element in addressing climatic changes and environmental hazards as it is cost and energy efficient.

\section{Acknowledgements}

The first author would like to thank Egyptian Ministry of Higher Education (MOHE) for providing him the financial support (PhD scholarship) for this research as well as the Egypt Japan University of Science and Technology (E-JUST) for offering the facility and tools needed to conduct this work.

\section{References}

[1] Sharaidin K, Kinetic F. Towards design for Environmental Performance. Ph.D. dissertation,Architecture and Design. RMIT University, Melbourne, Australia; 2014.

[2] Burry J, Burry M. Soft Responsive Kinetic System. In: Proc. 31st Annu. Conf. Assoc. Comput. Aided Des. Archit., 2011:334341.

[3] Ahmed MMS, Abel-Rahman AK, Ali AHH. Development of intelligent façade based on outdoor environment and indoor thermal comfort. Procedia Technol., 2015; 19:742-749.

[4] Wang J, Beltrán L, Kim J. From static to kinetic: a review of acclimated kinetic building envelopes. In: Proc. Ases.Conference-Services.Net, 2012:1-8.

[5] Velikov K, Thun G. Responsive building envelopes: Characteristics and evolving paradigms. Design and construction of highperformance homes: building envelopes. In: Proc. Renewable Energies and Integrated Practice, Routledge, 2013.

[6] Abdallah ASH, Hiroshi Y, Goto T, Enteria N, Radwan MM, Eid MA. Parametric investigation of solar chimney with new cooling tower integrated in a single room for New Assiut City, Egypt climate. Int. J. Energy Environ. Eng., 2014; 5:92.

[7] Fotiadou A. Analysis of design support for kinetic structures. Master of Science, Department of Building Physics and Building Ecology, Vienna, 2007.

[8] Khoo C, Salim F. Lumina: a soft kinetic material for morphing architectural skins and organic user interfaces. In: Proc. ACM Int. Jt., 2013:53-62.

[9] Khoo CK. Morphing architecture with responsive material systems. PhD thesis, RMIT University, Melbourne, Australia; 2013.

[10] Gorman MJ. Buckminster Fuller: Designing for Mobility. Milan: Skira, 2006:134.

[11] Hansanuwat R. Kinetic facades as environmental control systems: using kinetic facades to increase energy efficiency and building performance in office buildings. Dissertations \& Theses-Gradworks, May 2010.

[12] B. Happold. Hoberman Associates. (2010). Adaptive Building Initiative. [Online]. Available: www. adaptivebuildings.com

[13] Tashakori M. Sun-Tracking façade model. M.S. thesis. The Pennsylvania State University. Pennsylvania; 2014.

[14] Majed J. Design strategy for adaptive kinetic patterns : creating a generative design for dynamic solar shading systems. Master thesis. University of Salford. Manchester, UK; 2013.

[15] Loonen R. Climate adaptive building shells. What can we simulate? Master of Science Thesis. Architecture, Building \& Planning Eindhoven University of Technology; 2010.

[16] ASHRAE, ANSI/ASHRAE Standard 55-2010 Thermal Environmental Conditions for Human Occupancy; 2010.

[17] De Dear R, Brager GS. The adaptive model of thermal comfort and energy conservation in the built environment. Int. J. Biometeorol., 2001; 45:100-108.

[18] Teli D, Jentsch MF, James PAB. Naturally ventilated classrooms: an assessment of existing comfort models for predicting the thermal sensation and preference of primary school children. Energy Build., 2012; 53:166-182. 